\title{
Incidence of cancer in persons with occupational exposure to electromagnetic fields in Denmark
}

\author{
Pascal Guénel, Povl Raskmark, Jørgen Bach Andersen, Elsebeth Lynge
}

\begin{abstract}
Several studies suggest that work in electrical occupations is associated with an increased risk of cancer, mainly leukaemia and brain tumours. These studies may, however, not be representative if there is a publication bias where mainly positive results are reported. To study an unselected population the incidence of cancer was followed up over a 17 year period (1970-87) in a cohort of $2 \cdot 8$ million Danes aged 20-64 years in 1970. Each person was classified by his or her industry and occupation in 1970. Before tabulation of the data on incidence of cancer, each industryoccupation group was coded for potential exposure to magnetic fields above the threshold $0 \cdot 3 \mu \mathrm{T}$. Some 154000 men were considered intermittently exposed and 18000 continuously exposed. The numbers for women were 79000 and 4000 respectively. Intermittent exposure was not associated with an increased risk of leukaemia, brain tumours, or melanoma. Men with continuous exposure, however, had an excess risk of leukaemia (observed (obs) 39, expected (exp) 23.80, obs/exp 1.64, 95\% CI 1.20-2.24) with equal contributions from acute and other leukaemias. These men had no excess risk of brain tumours or melanoma. A risk for breast cancer was suggested in exposed men but not in women. The risk for leukaemia in continuously exposed men was mainly in electricians in installation works and iron foundry workers. Besides electromagnetic fields other
\end{abstract}

INSERM U88, 91, Boulevard de 1'hopital, F-75634, Paris Cedex 13, France

$\mathrm{P}$ Guénel

Aalborg University, Fredrik Bajers Vej 7, DK-9220 Aalborg $\varnothing$

P Raskmark, J B Andersen

Danish Cancer Society, Danish Cancer Registry, Rosenvæengets Hovedvej 35, Box 839, DK-2100 København Ø

E Lynge exposures should be considered as possible aetiological agents.

(British Fournal of Industrial Medicine 1993;50:758-764)

In the past decade several epidemiological studies have suggested that work in electrical occupations is associated with an increased risk of cancer, mainly leukaemia and brain tumours. ${ }^{1-3} \mathrm{~A}$ common hypothesis is that this cancer risk may be caused by exposure to $50 / 60 \mathrm{~Hz}$ electromagnetic fields. This hypothesis is supported by epidemiological casecontrol studies among children that reported associations between leukaemia or brain tumours and residence near overhead powerlines. ${ }^{4-7}$ The biological effects of electromagnetic fields suggest plausible mechanisms of carcinogenicity through cancer promotion, ${ }^{8}$ but experimental data do not provide direct evidence for a carcinogenic effect of electromagnetic fields. An appealing hypothesis was made by Stevens who suggested on the basis of experimental data that electromagnetic fields could enhance breast cancer through the inhibition of melatonin production by the pineal gland. ${ }^{9}$

The main weaknesses of the occupational studies include lack of exposure measurements and lack of control of potential confounding from other exposures. In a recent review, ${ }^{10}$ special attention was given to welders as arc welding produces simultaneously high levels of exposure to magnetic fields and to various other potential carcinogens. The absence of an excess leukaemia risk among welders is not consistent with the excess leukaemia risk in other electrical occupations. The review also showed a slight excess risk for brain tumours in this occupational group, however. In the same report it was suggested that the increased risks of cancer, especially for leukaemia, reported for electrical occupations could be due to publication bias in favour of positive results. The present study was undertaken to provide further data on the risk of cancer in occupations with potential exposure to electromagnetic fields. These data are unbiased as the study includes data on incidence of cancer for an entire national population for a $\mathbf{1 7}$ year period. 


\section{Material and methods}

POPULATION

The study includes people aged $20-64$ years at the census in Denmark on 9 November 1970. At the census information was collected on sex, age, and employment state, and industry and occupation were recorded for economically active persons. Industry was coded according to a modified version of the International Standard Industrial Classification covering 245 codes; and occupation was coded according to a special Danish code where a distinction was made between the self employed, family workers, salaried employees, skilled workers, and unskilled workers; a total of 218 codes was possible. ${ }^{11}$

\section{FOLLOW UP FOR DEATHS AND EMIGRATIONS}

Deaths and emigrations during the 17 year follow up period, 9 November 1970 to 8 November 1987, were identified by linkage with the Central Population Register, which holds information on all people who have lived in Denmark since $1968 .^{12}$

\section{FOLLOW UP FOR CANCER CASES}

Incident cancer cases during the 17 year follow up period were identified by linkage with the Danish Cancer Register, which holds information on all cancer cases diagnosed in Denmark since 1943.13 Cancer cases notified during 1970-7 were coded according to a modified version of the seventh revision of the International Classification of Diseases (ICD-7), ${ }^{14}$ whereas cancer cases notified from 1978 onwards were coded according to the International Classification of Diseases for Oncology (ICD-O). ${ }^{15}$ The ICD-O codes are translated to ICD-7 codes at registration, and ICD-7 codes were thus available for all cancer cases.

\section{EXPOSURE ASSESSMENT}

The classification for industry and occupation gives $53410(245 \times 218)$ possible combinations. In total, 8726 of these combinations were used for men aged 20-64 years, and 5539 of these combinations were used for women aged 20-64 years.

Some of these combinations represented groups with practically identical work tasks-for example, self employed with employees, self employed without employees, and (the largest group) self employed without information on employees, all in a given trade. When these groups were aggregated 8041 combinations remained for the men and 4336 combinations remained for the women.

Many of these industry-occupation combinations, however, were used for a few people only. We decided to exclude from the study all combinations that were used for less than 10 persons. After these exclusions, 3932 combinations remained for the men and 1885 combinations remained for the women.

Each of these industry-occupation combinations was coded for potential occupational exposure to alternating magnetic, alternating electric, and other fields. Only fields in the extremely low electromagnetic range were considered-that is, primarily fields at $50 \mathrm{~Hz}$. Based on publications ${ }^{5616-19}$ the threshold level for magnetic fields was assumed to be $0.3 \mu \mathrm{T}$. The codes used were:

(0) No exposure to fields (magnetic, electric, or other) higher than threshold levels.

(1) Probable exposure to intermittent (a few minute periods) magnetic fields higher than the threshold level.

(2) Probable exposure to magnetic fields continuously higher than threshold level.

(6) All situations not covered by the groups 0-2. This category should always be followed by a comment on the field type (static, transient, or microwave), and it should be stated whether there is a possible concurrent magnetic field.

The assessment of potential exposure in each of the industry-occupation combinations was based on a review of published studies ${ }^{17}{ }^{18-23}$ and a few field measurements. Other codes were possible during the coding but not used. They included magnetic fields higher than $100 \mu \mathrm{T}$, electric fields with a threshold level of $1 \mathrm{kV} / \mathrm{m}$, and concurrent magnetic and electric fields.

The coding was made independently by two of us (PR, JBA). Agreement between the two codings was found for 3262 of the 3932 combinations for men, and for 1589 of the 1885 combinations for women. The 670 combinations for men for which the coders disagreed represented $17 \%$ of the men, and the equivalent 296 combinations for women represented $13 \%$ of the women. A consensus coding was undertaken together by the two of us for the remaining combinations.

\section{TABULATION OF INCIDENCE OF CANCER}

For each exposure group the observed number of cancer cases and the person-years at risk were tabulated by sex and five year age groups defined by age at the time of the 1970 census.

Economically inactive persons are known in general to have a high disease rate, and only the cancer incidence rates for all economically active persons were therefore used for calculating the expected number of cancer cases. The relative cancer incidence was indicated by the observed number divided by the expected number and $95 \%$ two tailed confidence intervals (95\% CIs) were calculated under the assumption that the observed numbers followed a Poisson distribution, and for observed numbers over 30 a normal distribution. 
Table 1 The Danish population aged 20-64 years in 1970 by potential occupational exposure to magnetic, electric, and other fields

\begin{tabular}{|c|c|c|c|c|}
\hline Exposure & $\begin{array}{l}\text { No of } \\
\text { men } \\
\text { Industry- } \\
\text { occupation } \\
\text { combinations }\end{array}$ & $\begin{array}{l}\text { Persons } \\
\text { aged } \\
20-64\end{array}$ & $\begin{array}{l}\text { No of } \\
\text { women } \\
\text { Industry- } \\
\text { occupation } \\
\text { combinations }\end{array}$ & $\begin{array}{l}\text { Persons } \\
\text { aged } \\
20-64\end{array}$ \\
\hline $\begin{array}{l}\text { (0) Unexposed } \\
\text { (1) Probably magnetic, intermittent } \\
\text { (2) Probably magnetic, continuously } \\
\text { (6) Unspecified } \\
\text { Total coded } \\
\text { Industry-occupation with < } 10 \text { persons } \\
\text { Economically active persons } \\
\text { Economically inactive persons } \\
\text { Total population }\end{array}$ & $\begin{array}{r}3414 \\
407 \\
63 \\
\\
388 \\
3932 \\
4109 \\
8041 \\
-\end{array}$ & $\begin{array}{rr}1061 & 243 \\
154 & 138 \\
17977 \\
146205 \\
1279 & 563 \\
12 \\
12774 \\
1292337 \\
109630 \\
1401967\end{array}$ & $\begin{array}{r}1700 \\
120 \\
49 \\
16 \\
1885 \\
2451 \\
4336 \\
-\end{array}$ & $\begin{array}{rr}624 & 067 \\
79 & 005 \\
3 & 819 \\
16 & 313 \\
723 & 204 \\
7 & 343 \\
730 & 547 \\
671 & 676 \\
1402 & 223\end{array}$ \\
\hline
\end{tabular}

Within a given diagnostic group, only the first cancer case in a given person was considered.

Only the sites of cancer previously associated with the so called electrical occupations are examined in this paper. As well as leukaemia and brain tumours, which have been the most often investigated, excess risks for malignant melanoma and male breast cancers have also been reported. ${ }^{10}$

\section{Results}

Table 1 shows the distribution of the study population by exposure categories. An exposure category was assigned to $99 \%$ of the economically active men. Of these $83 \%$ were assumed to have no exposure to fields higher than the threshold level, $13 \%$ were assumed to have probable exposure to magnetic fields, and $4 \%$ were assumed to fall into category 6 with various exposures. An exposure category was also assigned to $99 \%$ of the economically active women. Most of these women (86\%) were assumed to have no occupational exposures to fields higher than the threshold level, $11 \%$ were assumed to have probable exposure to magnetic fields, and $2 \%$ were assumed to fall into the category 6 with various exposures. Most women in this last category belonged to inadequately described industries or occupations.

Table 2 lists the most numerous industry-occupation combinations classified as probably continuously exposed to magnetic fields. The difference between men and women should be noted.

The overall incidence of cancer was marginally raised in men with probable exposure to electromagnetic fields (table 3). Table 4 lists the incidence for the studied cancer sites for persons probably exposed to magnetic fields intermittently and continuously respectively. No significant result was

Table 2 The Danish population aged 20-64 years in 1970 and considered to be continuously exposed to electromagnetic fields in their work. List of the most numerous exposed groups

\begin{tabular}{|c|c|c|c|c|}
\hline $\begin{array}{l}\text { Occupation } \\
\text { code }\end{array}$ & Occupation & $\begin{array}{l}\text { Industry } \\
\text { code }\end{array}$ & Industry & $\begin{array}{l}\text { No } \\
\text { of } \\
\text { persons }\end{array}$ \\
\hline \multicolumn{5}{|c|}{ Men in exposed category 2} \\
\hline 385 & Electrician & 407 & Electricians, installation & 8780 \\
\hline 248 & Driver of electric vehicle & 701 & Railway transport & 1791 \\
\hline 416 & Foundry worker, machine moulder & 341 & Iron foundries & 1307 \\
\hline 385 & Electrician & 511 & Electric light and power & 1239 \\
\hline 258 & Programmer, systems planner & 846 & Electronic data processing services & 919 \\
\hline 385 & Electrician & 379 & Manufacture of electrical machinery and equipment & 872 \\
\hline 257 & EDB and punched card operator & 846 & Electronic data processing services & 621 \\
\hline 293 & Chief engineer, assistant engineer ashore & 511 & Electric light and power ashore & 523 \\
\hline 257 & EDB and punched card operator & 690 & Banks, mortgage credit associations & 132 \\
\hline 258 & Programmer, systems planner & 695 & Insurance & 124 \\
\hline \multicolumn{5}{|c|}{ Women in exposed category 2} \\
\hline 257 & EDB and punched card operator & 846 & Electronic data processing services & 709 \\
\hline 287 & Shop assistant & 610 & Dairy products and bread & 651 \\
\hline 257 & EDB and punched card operator & 690 & Banks, mortgage credit associations & 432 \\
\hline 257 & EDB and punched card operator & 695 & Insurance & 172 \\
\hline 258 & Programmer, systems planner, systems analyst & 846 & Electronic data processing services & 160 \\
\hline 257 & EDB and punched card operator & 605 & Other wholesale trade proper & 154 \\
\hline 257 & EDB and punched card operator & 609 & Depots, auctioneering & 73 \\
\hline 257 & EDB and punched card operator & 365 & Engineering works & 64 \\
\hline
\end{tabular}


Table 3 Cancer incidence 1970-87 in the Danish population aged 20-64 years in 1970 by potential exposure to magnetic, electric, and other fields. All cancer ICD-7 140-205

\begin{tabular}{|c|c|c|c|c|c|c|c|c|}
\hline \multirow[b]{2}{*}{ Exposure group } & \multicolumn{4}{|l|}{ Men } & \multicolumn{4}{|l|}{ Women } \\
\hline & $O b s$ & $\operatorname{Exp}$ & $\begin{array}{l}\text { Obs/ } \\
\exp \end{array}$ & $95 \% C I$ & Obs & $\operatorname{Exp}$ & $\begin{array}{l}\text { Obs } \\
\text { exp }\end{array}$ & $95 \% C I$ \\
\hline $\begin{array}{l}\text { Economically active in } 1970 \\
\text { (0) Unexposed } \\
\text { (1) Magnetic intermittent } \\
\text { (2) Magnetic continuously } \\
\text { (6) Unspecified } \\
\text { Less than } 10 \text { persons } \\
\text { Economically inactive in } 1970 \\
\text { All persons }\end{array}$ & $\begin{array}{r}104105 \\
87738 \\
11351 \\
846 \\
2980 \\
1190 \\
9429 \\
113534\end{array}$ & $\begin{array}{r}104106 \\
88748 \\
10734 \\
812 \\
2741 \\
1071 \\
8596 \\
112702\end{array}$ & $\begin{array}{l}1 \cdot 00 \\
0 \cdot 99 \\
1 \cdot 06 \\
1 \cdot 04 \\
1 \cdot 09 \\
1 \cdot 11 \\
1 \cdot 10 \\
1 \cdot 01\end{array}$ & $\begin{array}{l}- \\
0 \cdot 98-1 \cdot 00 \\
1 \cdot 04-1 \cdot 08 \\
0.97-1 \cdot 11 \\
1 \cdot 05-1 \cdot 13 \\
1 \cdot 05-1 \cdot 17 \\
1 \cdot 08-1 \cdot 12 \\
1 \cdot 00-1 \cdot 02\end{array}$ & $\begin{array}{r}55364 \\
47096 \\
6135 \\
210 \\
1285 \\
638 \\
63141 \\
118505\end{array}$ & $\begin{array}{r}55365 \\
47399 \\
5987 \\
215 \\
1180 \\
584 \\
64369 \\
119734\end{array}$ & $\begin{array}{l}1.00 \\
0.99 \\
1.02 \\
0.98 \\
1.09 \\
1.09 \\
0.98 \\
0.99\end{array}$ & $\begin{array}{l}- \\
0.98-1.00 \\
0.99-1.03 \\
0.56-1 \cdot 12 \\
1.03-1 \cdot 15 \\
1.01-1 \cdot 18 \\
0.97-0.99 \\
0.98-1.00\end{array}$ \\
\hline
\end{tabular}

found for breast cancer, melanoma, or brain tumours. The incidence of leukaemia was significantly increased in men with probable, continuous exposure to magnetic fields (obs 39, exp 23.80, obs/exp $1 \cdot 64,95 \%$ CI $1 \cdot 20-2 \cdot 24)$. The raised risks were at the same level for acute leukaemia (obs 16, $\exp 10 \cdot 14$, obs/exp $1 \cdot 58,95 \%$ CI $0 \cdot 90-2 \cdot 56)$ and for other leukaemias (obs 23, exp 13.72, obs/exp $1 \cdot 68$, 95\% CI 1.06-2.52). The incidence of leukaemia was not increased in the small group of women with continuous exposure to magnetic fields (obs 2, exp 3.55, obs/exp 0.56, 95\% CI $0 \cdot 07-2 \cdot 03)$. Both men and women with probable intermittent exposure to magnetic fields had leukaemia risks close to the average for all economically active persons with obs/exp of 0.94 and 0.92 respectively.

A separate tabulation of the incidence of leukaemia was made for the industry-occupation combinations in table 2 with more than 500 men. Electricians working in electrical installation work shops had an excess leukaemia risk (obs 16, exp $8 \cdot 19$, obs/exp $1 \cdot 95,95 \%$ CI $1 \cdot 12-3 \cdot 17$ ), and so had foundry workers/machine moulders in iron foundries (obs 9, exp 3.10, obs/exp $2 \cdot 90,95 \%$ CI
1.33-5.51). The leukaemia risk was not increased in drivers of electric rails (obs 5, exp 5.06, obs/exp $0 \cdot 99$, 95\% CI $0 \cdot 32-2 \cdot 31$ ), nor in electricians working in electric light and power stations (obs 3, exp $2 \cdot 44$, obs/exp 1.23, 95\% CI 0.25-3.59). No case of leukaemia was found in the two groups of data processing workers with more than 500 men, and in total only 0.94 cases were expected. The data processing workers were relatively young in 1970 . The two remaining groups with more than 500 men together had two observed leukaemia cases and $2 \cdot 28$ expected.

\section{Discussion}

This study shows that men with potential continuous exposure to magnetic fields had an increased incidence of leukaemia. The incidence of cancer at the other sites was close to the expected in both men and women with potential exposure to magnetic fields.

The evidence of a possible carcinogenic effect of occupational exposure to electric or magnetic fields comes from observations of increased mortality or morbidity from cancer in occupational groups

Table 4 Cancer incidence 1970-87 in the Danish population aged 20-64 years in 1970 with probable exposure to magentic fields. Selected cancer sites

\begin{tabular}{|c|c|c|c|c|c|c|c|c|c|}
\hline \multirow[b]{2}{*}{$\begin{array}{l}I C D- \\
7\end{array}$} & \multirow[b]{2}{*}{ Cancer site } & \multicolumn{4}{|c|}{ Magnetic, intermittent } & \multicolumn{4}{|c|}{ Magnetic, continuously } \\
\hline & & Obs & $\operatorname{Exp}$ & $\begin{array}{l}\text { Obs/ } \\
\exp \end{array}$ & $95 \% C I$ & Obs & $\operatorname{Exp}$ & $\begin{array}{l}\text { Obs/ } \\
\exp \end{array}$ & $95 \% C I$ \\
\hline $\begin{array}{l}\text { Men: } \\
170 \\
190 \\
193 \\
204\end{array}$ & $\begin{array}{l}\text { Breast } \\
\text { Melanona } \\
\text { Brain and nervous system } \\
\text { Leukaemia } \\
\text { Acute leukaemia } \\
\text { Other leukaemia }\end{array}$ & $\begin{array}{l}23 \\
217 \\
339 \\
282^{\star} \\
119 \\
164\end{array}$ & $\begin{array}{r}18 \cdot 88 \\
257 \cdot 87 \\
360 \cdot 59 \\
300 \cdot 12 \\
117 \cdot 69 \\
183 \cdot 10\end{array}$ & $\begin{array}{l}1 \cdot 22 \\
0.84 \\
0.94 \\
0.94 \\
1.01 \\
0.90\end{array}$ & $\begin{array}{l}0.77-1.83 \\
0.74-0.96 \\
0.85-1.05 \\
0.84-1.06 \\
0.84-1.21 \\
0.77-105\end{array}$ & $\begin{array}{r}2 \\
21 \\
23 \\
39 \\
16 \\
23\end{array}$ & $\begin{array}{r}1 \cdot 47 \\
25 \cdot 36 \\
33 \cdot 33 \\
23 \cdot 80 \\
10 \cdot 14 \\
13 \cdot 72\end{array}$ & $\begin{array}{l}1.36 \\
0.83 \\
0.69 \\
1.64 \\
1.58 \\
1.68\end{array}$ & $\begin{array}{l}0 \cdot 16-4 \cdot 91 \\
0 \cdot 51-1 \cdot 27 \\
0 \cdot 44-1 \cdot 04 \\
1 \cdot 20-2 \cdot 24 \\
0 \cdot 90-2 \cdot 56 \\
1 \cdot 06-2 \cdot 52\end{array}$ \\
\hline $\begin{array}{l}170 \\
190 \\
193 \\
204\end{array}$ & $\begin{array}{l}\text { Breast } \\
\text { Melanona } \\
\text { Brain and nervous system } \\
\text { Leukaemia } \\
\text { Acute leukaemia } \\
\text { Other laukaemia }\end{array}$ & $\begin{array}{r}1526 \\
180 \\
198 \\
94 \\
47 \\
47\end{array}$ & $\begin{array}{r}1596 \cdot 51 \\
197 \cdot 41 \\
184 \cdot 57 \\
102 \cdot 13 \\
50 \cdot 71 \\
51 \cdot 50\end{array}$ & $\begin{array}{l}0.96 \\
0.91 \\
1.07 \\
0.92 \\
0.93 \\
0.91\end{array}$ & $\begin{array}{l}0.91-1 \cdot 01 \\
0 \cdot 79-1 \cdot 05 \\
0.93-1 \cdot 23 \\
0 \cdot 75-1 \cdot 13 \\
0 \cdot 70-1 \cdot 24 \\
0.68-1 \cdot 21\end{array}$ & $\begin{array}{r}55 \\
6 \\
9 \\
2 \\
1 \\
1\end{array}$ & $\begin{array}{r}62 \cdot 56 \\
8 \cdot 87 \\
7 \cdot 30 \\
3.55 \\
1.90 \\
1.66\end{array}$ & $\begin{array}{l}0.88 \\
0.68 \\
1.23 \\
0.56 \\
0.53 \\
0.60\end{array}$ & $\begin{array}{l}0.68-1 \cdot 15 \\
0.25-1.47 \\
0.56-2.34 \\
0.07-2.03 \\
0.01-2.93 \\
0.02-3.36\end{array}$ \\
\hline
\end{tabular}

*One patient was diagnosed with both an acute and another leukaemia and the total number of patients with leukaemia is therefore one less than $119+164$. 
working with electricity. At least 60 different epidemiological studies of electrical workers have been published. Proportionate mortality or incidence studies, and case-control studies carried out from mortality or morbidity registers generally showed greater excess risk than cohort studies for leukaemia and brain tumours. ${ }^{31024}$ Proportionate and case-control studies have been criticised because of possible selection biases, which are less likely to occur in cohort studies. ${ }^{24}$ Our present study was a cohort design.

In an extensive review, ${ }^{10}$ the combined results of cohort studies showed only small excess risks for leukaemia (odds ratio $(O R)=1 \cdot 15$ ) and brain tumours $(O R=1 \cdot 10)$. The corresponding results from proportionate mortality studies were proportionate mortality ratio (PMR) $=108$ for leukaemia and $P M R=123$ for brain tumours. Somewhat stronger evidence of an excess risk was found from the case-control studies (combined figures not given). In an earlier review, ${ }^{2}$ the small risk of all leukaemia (relative risk $(R R)=1 \cdot 2$ ), calculated from 11 studies was stronger for acute myeloid leukaemia $(R R=1 \cdot 5)$. In addition, recent studies reported an increased risk of chronic myeloid leukaemia in a large cohort of Norwegian electrical workers (standardised incidence ratio $($ SIR) $=$ 197), ${ }^{25}$ and an increased risk of chronic lymphatic leukaemia in a Swedish case-control study where magnetic fields were measured at the workplace $(R R=3.08) .{ }^{26}$ No clear association with brain tumours was seen in these studies. Increased risks have also been reported for malignant melanoma, ${ }^{27-30}$ and more recently for male breast cancer. ${ }^{31-33}$

In the first report of this series of publications, ${ }^{34}$ the main occupations associated with electricity included electricians, welders and flame cutters, aluminium workers, power and telephone linemen, electrical engineers, electronic technicians, radio and telegraph operators, and power station operators. ${ }^{21}$ It is reasonable to assume that the exposure to magnetic fields is above background for occupations such as welders for whom particularly high exposures have been documented ${ }^{35}$ or for some electric utility workers. ${ }^{17}$ The exposure of broadly defined occupational groups such as electricians is more conjectural. Lack of exposure data and differences in occupational nomenclatures make the comparison between studies difficult.

In Denmark, combinations of industry and occupation were coded for exposure to magnetic fields. The industry and occupation classifications allow certain jobs such as foundry workers/machine moulders in iron foundries to appear distinctly. Welders, however, were classified into a broader group of metal workers. For each combination an attempt was made to code the average level of exposure ( $\leqslant$ threshold, intermittent, or continuous exposure $>$ threshold) so that an increase in risk with an increasing level of exposure could eventually be evaluated.

Because the exposure varies between workers in the same industry-occupation combination, the assignment of workers to an exposure category involves some degree of misclassification. Welders, being part of the broader group of metal workers, were coded as intermittently exposed because the average exposure for the broad group was considered to be too infrequent to warrant coding as continuously exposed. This misclassification tends to lower the risk estimation. Therefore, positive results cannot be explained on this basis. Conversely, positive confounding from other occupational exposures could not be examined, and this limitation should be taken into account in the interpretation of the data.

The increase in incidence of leukaemia for men in the continuous exposure category was not confirmed by a concordant increase in the intermittent exposure category. The group of women in the continuous exposure category was too small for the data to be conclusive. In men with continuous exposure no specific association was found with a particular subtype of leukaemia. Electricians in installation workshops and iron foundry workers provided most of the excess risk. Electricians in installation workshops install, repair, and maintain electric light, ventilation and heating systems, elevators, motors etc. Some electricians are also responsible for maintaining the low voltage distribution lines. As well as electromagnetic fields they have been exposed to such things as soldering fumes, lead, and organic solvents.

Some of the iron foundry workers are assumed to work near $50 \mathrm{~Hz}$ induction furnaces where a very high field exists. ${ }^{22}$ The use of high frequency induction heating is, however, also common. Also, iron foundry workers may also be exposed to, for example, silica, polynuclear aromatic hydrocarbons, chromium and nickel compounds, phenols, formaldehyde, or amines. ${ }^{36}$ Most of these other exposures are suspected to cause respiratory cancer, not leukaemia. Further investigations on this group, however, require consideration of all exposures.

By contrast, occupational subgroups such as electrical railroad drivers or electricians in electrical light and power plants had an incidence of leukaemia close to the expected. Most of the electrical railways in Denmark operate with direct current, and only a small part involves exposure to $\mathbf{5 0}$ $\mathrm{Hz}$ magnetic fields. Railroad drivers, however, are not likely exposed to potentially carcinogenic chemicals.

In total, probable differences in the nature or level of exposure to magnetic fields can explain the 
difference in leukaemia risk between the exposed subgroups. The possibility that electromagnetic fields enhance risk of cancer in conjunction with other occupational exposures through cancer promotion, ${ }^{37}$ should also be considered. Magnetic fields cannot be regarded as responsible for the risk of leukaemia, however, as long as the possible confounding from other exposures has not been definitely eliminated.

Brain tumours have shown greater excess risk among electrical occupations than leukaemia, especially among welders. ${ }^{10}$ Some evidence of an increased risk with increased duration of employment was provided by Thomas et al, ${ }^{38}$ but emphasis was made in this study on the possibility of confounding from other occupational exposures. In the present study, the incidence of brain tumours was decreased in both exposure categories for men, and close to statistical significance in the continuous exposure category. The slight excess risks in women are far from statistical significance. In total, this study does not confirm an excess risk of brain tumours in occupations exposed to magnetic fields.

Several studies have reported an excess risk of melanoma. ${ }^{25-28}$ The incidence of melanoma was close to expected in this study, and it thus indicates that chance finding is a possible explanation for the association observed previously.

Unlike other cancer sites, there is some experimental evidence linking breast cancer to exposure to electromagnetic fields. The hypothesis suggested by Stevens ${ }^{9}$ postulates that electric and magnetic fields could cause breast cancer through the inhibition of melatonin production by the pineal gland. It has been shown that the normal rise in melatonin at night is suppressed by $60 \mathrm{~Hz}$ electric fields in rats. Other experiments suggest that reduced melatonin production may enhance mammary carcinogenesis through different possible mechanisms (for example, increase in oestrogen concentrations and stimulation of breast tissue proliferation). ${ }^{39}$ Three occupational studies among men exposed to electromagnetic fields have shown increased risks of male breast cancers. In a first cohort study of over 50000 United States telephone workers there were two incident cases of breast cancer among central office technicians leading to a non-significant standardised incidence ratio (SIR) of $6 \cdot 5 .{ }^{32} \mathrm{In}$ another cohort study of the Norwegian male population followed up from the 1960 census to 1985 , men in occupations associated with electromagnetic fields had an SIR of 2.07 for breast cancer (based on 12 observed cases). ${ }^{31}$ Finally, in a case-control study on 227 incident male breast cancers from 10 cancer registries in United States and 300 populations controls, the odds ratio for all electrical occupations was $1.8(95 \% \mathrm{CI}=1 \cdot 0-3 \cdot 07) .^{33}$

The present study indicates a slightly raised risk of male breast cancer. Combining the results of both exposure categories leads to a non-significant observed to expected ratio of $1.23(95 \% \mathrm{CI}=$ $0 \cdot 79-1 \cdot 81)$. Conversely, in the much more numerous groups of exposed women, there was a slight deficit of observed cases leading to a ratio of less than 1 . By contrast with the results in men, a casecontrol study in postmenopausal women found an OR of $0.89(95 \% \mathrm{CI}=0.66-1 \cdot 19)$ for breast cancer in women with prolonged exposure to magnetic fields due to daily use of electric blankets. ${ }^{40}$

In total, this study supports the previous findings of an increased risk of leukaemia in some occupations working with electricity. A slight excess risk for male breast cancer was suggested, but it was not confirmed by a concordant increase among women. The study showed no risk of brain tumours or melanoma. The reason for the increased risk of leukaemia is not clear. Besides electromagnetic fields other occupational exposures may explain the finding. Ongoing studies including measurements of exposure to electric and magnetic fields and assessment of exposure to chemicals will shed further light on these possible aetiological agents.

This study was financially supported by the EC concerted action on "Retrospective Evaluation of Occupational Exposures in Cancer Epidemiology."

1 Coleman M, Beral V. A review of epidemiological studies of the health effects of living near or working with electricity generation and transmission equipment. Int $f$ Epidemiol 1988;17:1-13.

2 Savitz DA, Calle EE. Leukaemia and occupational exposure to electromagnetic fields: review of epidemiologic surveys. $\mathcal{F}$ Occup Med 1987;29:47-51.

3 Thériault G. Electromagnetic fields and cancer risks. Rev Epidemiol Santé Publique 1992;40:S55-S62.

4 Wertheimer N, Leeper E. Electrical wiring configurations and childhood cancer. Am f Epidemiol 1979;109:273-84.

5 Tomenius L. $50-\mathrm{Hz}$ electromagnetic environment and the incidence of childhood tumors in Stockholm county. Bioelectromagnetics 1986;7:191-207.

6 Savitz DA, Watchel H, Barnes FA, John EM, Turdik JG. Case-control study of childhood cancer and exposure to 60$\mathrm{Hz}$ magnetic fields. Am $\mathcal{F}$ Epidemiol 1988;128:21-38.

7 London SJ, Thomas DC, Bowman JD, Sobel E, Cheng TC, Peters JM. Exposure to residential electric and magnetic fields and risk of childhood leukaemia. Am $\mathcal{F}$ Epidemiol 1991;134:923-37.

8 Easterly CE. Cancer link to magnetic field exposure: a hypothesis. Am $\mathcal{F}$ Epidemiol 1981;114:169-74.

9 Stevens R. Electric power use and breast cancer: a hypothesis. Am $\mathcal{F}$ Epidemiol 1987;125:556-61.

10 Advisory Group on Non-ionising Radiation. Electromagnetic fields and the risk of cancer. Documents of the NRPB vol 3 No 1, 1992. Chilton, Didcot, Oxon OX11 ORQ: National radiological Protection Board, 1992.

11 Lynge E, Thygesen L. Occupational cancer in Denmark. Cancer incidence in the 1970 census population. Scand $\mathcal{F}$ Work Environ Health 1990;16 (suppl 2): 1-35.

12 National Centre for Health Statistics. The person number systems of Sweden, Norway, Denmark, and Israel. Hyattsville: DHHS, 1980. (Vital Health Statistics Ser-2 No 84, DHHS Publ PHS 80-1358.)

13 Jensen OM, Storm HH, Jensen $H$. Cancer registration and the study of multiple primary cancers in Denmark 1943-80. 
National Cancer Institute Monographs 1985;68:245-51.

14 Clemmesen J. Statistical studies in the aetiology of malignant neoplasms IV, Denmark 1943-67. Acta Pathologica Microbiologica Scandinavica 1974;(suppl); 247:1-266.

15 World Health Organisation. International classification for oncology. ICD-O. Geneva: WHO, 1976.

16 Kaune WT, Stevens RG, Callahan NJ, Severson RK, Thomas DB. Residential magnetic and electric fields. Bioelectromagnetics 1987;8:315-35.

17 Deadman JE, Camus M, Armstrong BG, Héroux P, Cyr D Plante $M$, Thériault $G$. Occupational and residential $60-\mathrm{Hz}$ electromagnetic fields and high frequency electric transients: Exposure assessment using a new dosimeter. Am Ind Hyg Assoc ₹ 1988;49:409-19.

18 Stuchly MA. Human exposure to static and time-varying magnetic fields. Health Physics 1986;51:215-25.

19 Environmental Protection Agency. Summary and conclusion of EPA's EMF cancer report. Microwave News 1990;10:11-5.

20 Lin RS, Dischinger PC, Conde J, Farrell KP. Occupational exposure to electromagnetic fields and the occurrence of brain tumors. 7 Occup Med 1985;27:413-9.

21 Bowman JD, Garabrant DH, Sobel E, Peters JM. Exposures to extremely low frequency (ELF) electromagnetic fields in occupations with elevated leukemia rates. Applied Industrial Hygiene 1988;3:189-94.

22 Lövsund P, Öberg PA, Nilsson SEG. ELF Magnetic fields in electro-steel and welding industries. Linköpings University, Sweden: Departments of Biomedical Engineering and Ophthalmology, 1984; 2-15.

23 Stenlund C, Lindh T, Floderus B, Knave B. Mätning av magnetfält på tåg. Arbetsmiljöinstituttet. (Measurements of magnetic fields on trains). Undersökelsesrapport 1989;10:1-12.

24 Poole C, Trichopoulos D. Extremely low-frequency electric and magnetic fields and cancer. Cancer Cause Control $1991 ; 2: 267-76$

25 Tynes T, Andersen A, Langmark F. Incidence of cancer in Norwegian workers potentially exposed to electromagnetic fields. Am $\Im$ Epidemiol 1992;136:81-8.

26 Floderus B, Persson T, Stenhund C, et al. Occupational exposure to electromagnetic fields in relation to leukaemia and brain tumours. A case control study. Solna: National
Institute of Occupational Health, 1992; 1-20.

27 Swerdlow AJ. Epidemiology of eye cancer in adults in England and Wales, 1962-1977. Am f Epidemiol 1983;118:294-300.

28 Olin R, Vagero D, Ahlbom A. Mortality experience of electrical engineers. $B r f$ Ind $M e d$ 1985;42:21 1-12.

29 Vagerö D, Ahlbom A, Olin R, Sahlsten S. Cancer morbidity among workers in the telecommunication industry. $\mathrm{Br} F$ Ind Med 1985;42:191-5.

30 de Guire L, Thériault G, Iturra H, Provencher S, Cyr D, Case $\mathrm{BW}$. Increased incidence of malignant melanoma of the skin in workers in a telecommunication industry. $\mathrm{Br} \mathcal{F}$ Ind Med 1988;45:824-8.

31 Tynes $T$, Andersen A. Electromagnetic fields and male breast cancer. Lancet 1990;336:1596.

32 Matanosiki GM, Breysse PN, Elliott EA. Electromagnetic field exposure and male breast cancer. Lancet 1991;337:737.

33 Demers PA, Thomas DB, Rosenblatt KA, et al. Occupational exposure to electromagnetic fields and breast cancer in men. Am $\mathcal{F}$ Epidemiol 1991;134:340-7.

34 Milham S. Mortality from leukaemia in workers exposed to electrical and magnetic fields. N Engl ₹ Med 1982;307:249.

35 Stuchly MA, Lecuyer DW. Exposure to electromagnetic fields in arc welding. Health Physics 1989;56:297-302.

36 Iron and steel founding. In: LARC monographs on the evaluation of the carcinogenic risk of chemicals to humans. Vol 34. Lyon: International Agency for Research on Cancer 1984; 133-90.

37 Adey WR. Joint actions of environmental non-ionizing electromagnetic fields and chemical pollution in cancer promotion. Environ Health Perspect 1990;86:297-305.

38 Thomas TL, Stolley PD, Stemhagen A, Fontham ETH, Bleecker ML, Stewart PA, Hoover RN. Brain tumor risk in the electrical and electronics industries. $\mathcal{F}$ Natl Cancer Inst 1987;79:233-8.

39 Stevens RG, Davis S, Thomas DB, Anderson LE, Wilson BW. Electric power, pineal function, and the risk of breast cancer. Faseb $\mathcal{F}$ 1992;6:853-60.

40 Vena JE, Graham S, Hellman R, Swanson M, Brasure J. Use of electric blankets and risk of postmenopausal breast cancer. Am F Epidemiol 1991;134:180-5.

Accepted 9 November 1992 